the property that each particular motion, when continued indefinitely, passes through every configuration and state of motion of the system which is compatible with the value of the total energy. The assumption that the systems considered in the kinetic theory of gases are ergodic was made by Maxwell and Boltzmann. Birkhoff in 1931 published a fundamental result which he called the "ergodic theorem", and which may be stated as follows. For any dynamical system which satisfies certain conditions (which, in fact, are generally satisfied by the systems occurring in theoretical physics), there is a definite 'time probability' that any moving point, except those of a set of measure zero, will be in an assigned region $v$; that is, if $t$ denotes the total interval of time elapsed from a fixed instant, and $\bar{t}$ the sum of the portions of this interval during which the point of the trajectory lies in $v$, then $(\bar{t} / t)$ tends to a definite limit. This theorem, which Birkhoff proved by aid of an essentially new algorithm, goes far towards supplying a rigorous foundation for statistical mechanics.

In later life, Birkhoff became interested in the discovery of mathematical relations concerned with rsthetics, and in a new theory of gravitation. His miscellaneous papers range over an immense variety of topics; and the long list of doctorate theses directed by him, containing many names of men who are now in the front rank, shows in a striking fashion the great part that he played in forming the present generation of American mathematicians.

EDMUND T. WhitTaker

\section{MEGALITHS OF ENGLAND AND WALES}

The Prehistoric Chamber Tombs of England and Wales

By Dr. Glyn E. Daniel. Pp. xiv $+256+16$ plates, (Cambridge: At the University Press, 1950.) 31s.6d. net.

THE numerous standing stones, dolmens, barrows 1 and other forms of megaliths which can be seen in various parts of Britain have always been objects of great interest not only to the prehistorian, but also to everyone who either lives in a district where they occur or who comes across them when travelling or on holiday. Dr. Glyn E. Daniel has put us all in his debt by preparing this detailed and comprehensive account of the chamber tombs, and where they are found and how they can be classified. The work is fully illustrated with diagrams, maps and photographs, and contains a wealth of information. Anyone, whether student or interested amateur, who proposes to visit an area where these constructions occur would do well to take Dr. Daniel's book with him : he will find it invaluable.

The opening chapter is concerned with the distribution of the monuments, and the geographical conditions of the period. Evidence is marshalled to show that we must consider their distribution "against the background of a Britain with a coastline extending to the present 5- or even 10-fathom line, and a heavily forested countryside". An account of the methods of construction follows, and then a chapter which deals with the various different forms of tomb which are found; because all chamber-tombs are by no means the same in plan nor have they all the same origin. An interesting chapter on ritual and symbolism comes next. Why is there a burial at Notgrove and again at Bryn Celli Ddee, inaccessible from the passages, which themselves contain numerous bones? What is the meaning of the pillar at the latter site which upholds nothing ? Can we get any evidence as to what were the ceremonies practised when these monuments were in use ? What is the interpretation of the engravings occasionally found on the walls within the tombs? Not all these queries can be answered ; much must be guesswork, but Dr. Daniel at any rate tackles the problems. The stone at Bryn Celli Ddee, buried in the central pit and not to be reached by the passage, is covered with zigzag markings which closely resemble those on a pointed headstone in a barrow in north Spain. It also appears to have Irish connexions. Again, the interlocked concentric circles at Sess Kilgreen in Co. Tyrone-rather than any found at Loch Crew as suggested by Dr. Daniel-are very similar to the carvings on the walls at Gavr'inis in the Morbihan, Brittany; but any art on the megaliths in this latter country is rare, and even in Ireland there is only the one group that is much decorated. A chapter on the archæological finds associated with the monuments follows. I always have a sneaking feeling that in some cases, where objects of late date oceur in association with the constructions, the association is real and not fortuitous-that the megaliths were actually of late date though belonging to the more ancient culture which had continued to survive. It is just when we are dealing with death that man is most conservative and that ancient traditional practices tend to continue even after their parent culture has in other respects undergone change. Finally, there is a chapter on origins and dating, and an excellent inventory of sites which forms Part 2 of the book and which will be especially useful both for reference and as a "Baedeker" for the monuments.

Dr. Daniel is a scholar, and his "Prehistoric Chamber Tombs of England and Wales" is a notable contribution to the literature of his subject. M. C. BurkitT

\section{TEXT-BOOK OF PLANT PHYSIOLOGY}

An Introduction to Plant Physiology

By Otis F. Curtis and Prof. Daniel G. Clark. (McGraw-Hill Publications in the Botanical Sciences.) Pp. xiii+752. (London: McGraw-Hill Publishing Co., Ltd., 1950.) 55s. $6 d$.

T now seems to be pretty generally agreed that 1 plant physiology covers an uncomfortably wide field to be dealt with, even at an intermediate level, by a single author, and it is usual to find more than one name on the title page of a text-book, or numerous acknowledgments of help received. Reviewing has not yet been put similarly into commission, and it is perhaps inevitable that any attempt at a critical evaluation should be biased by' the reviewer's own competencies and predilections. It therefore seems more profitable to speak of the general approach of Profs. Curtis and Clark to their subject rather than to dissect particular chapters of their book.

It is immediately obvious that the authors have spent much thought and care on their didactic method; and it is not without reason that they have made their dedication to the generations of their students. It is easy to believe that for them the 